\title{
Identifikasi Risiko Kecelakan Kerja Terhadap Pekerja Di PT. IKI Makassar Tahun 2020 (Studi Pada Pekerja Proses Marking)
}

\author{
*Rifdah Mufiidah Rusli ${ }^{1}$, Suharni A. Fachrin ${ }^{2}$ dan Andi Asrina ${ }^{3}$ \\ 1,2,3 Program Pascasarjana Kesehatan Masyarakat Universitas Muslim Indonesia \\ Email: rifdahmufiidah05@gmail.com
}

\begin{abstract}
Introduction: Management of occupational health and safety is an integrated effort to manage the risks involved in company activities that can resulted in human injury, damage or disruption to the company's business is divided into three parts, namely Hazard Identification, Risk Assessment and Risk Control (HIRARC) aims to identify potential hazards in the workplace by linking workers, tasks, work equipment and the work environment. The purpose of this study was to identify occupational accident risk then assess the level of occupational accident risk at PT. IKI Makassar in 2020 and how to control it. Methods: The research is qualitative. The approach used in this research is a quasi-qualitative approach. The technique used is observation, in-depth interview) and documentation continuously throughout the study to analyze further about risk identification and control that can be done in the marking process at PT. IKI Makassar. Prior to qualitative research, the risk management process was measured using the HIRARC. The informants in this study were divided into three, that are key informants is the inspector K3, regular informants (part of production process management and knowing the flow of the marking production process), and supporting informants (the workers who work in part of the marking production process) at PT. IKI Makassar. Results: From the results of the study using the HIRARC (Hazard Identification, Risk Assessment and Risk Control) table, it was found that the highest potential hazards and risks were found in the marking process in cutting plates where the most frequent potential hazards such as slipping, falling, slicing and scratching. The conclusion of this research is the Potential dangers contained in the marking process at PT. Makassar IKI covers mechanical hazards in the marking area, ie pinched, dropped, scratched, sliced, knocked and crushed
\end{abstract}

Keywords: HIRARC, Hazard Identification, Pipe Cutting, Cutting Plate 


\begin{abstract}
ABSTRAK
Latar belakang: Manajemen K3 penting dilakukan untuk mengelola risiko yang ada dalam aktivitas perusahaan yang dapat mengakibatkan cidera pada manusia, kerusakan atau gangguan terhadap bisnis perusahaan yang terbagi atas tiga bagian yaitu Hazard Identification, Risk Assessment and Risk Control (HIRARC) yang bertujuan untuk mengidentifikasi potensi bahaya di tempat kerja. Tujuan penelitian ini adalah untuk melakukan identifikasi risiko kecelakaan kerja kemudian menilai tingkat risiko kecelakaan kerja di PT. IKI Makassar Tahun 2020 dan cara pengendaliannya. Metode: Jenis penelitian yang digunakan yaitu kualitatif dengan pendekatan quasi kualitatif. Tehnik yang digunakan adalah observasi, wawancara mendalam (Indepth Interview) dan dokumentasi secara terus menerus selama penelitian berlangsung untuk menganalisis lebih dalam tentang identifikasi risiko dan pengendalian yang dapat dilakukan pada proses marking di PT. IKI Makassar. Sebelum dilakukan penelitian secara kualitatif, proses manajemen risiko diukur menggunakan metode HIRARC (Hazard Identification, Risk Assessment and Risk Control). Informan dalam penelitian ini terbagi tiga yaitu informan kunci yaitu inspektor K3, informan biasa (bagian dari manajemen proses produksi dan mengetahui alur proses produksi marking), dan informan pendukung (pekerja yang bekerja di bagian proses produksi marking) di PT. IKI Makassar. Hasil: Dari hasil penelitian menggunakan tabel HIRARC (Hazard Identification, Risk Assessment and Risk Control) diperoleh bahwa potensi bahaya dan risiko tertinggi terdapat pada proses marking dalam pemotongan plat dimana potensi bahaya yang paling sering terjadi seperti terpeleset, terjatuh, teriris, dan tergores. Kesimpulan: Potensi bahaya yang terdapat pada proses marking di PT. IKI Makassar meliputi bahaya mekanik yang ada pada area marking yaitu terjepit, terjatuh, tergores, teriris, terbentur dan tertimpa.
\end{abstract}

Kata Kunci: HIRARC, Identifikasi bahaya, Pemotongan pipa, dan Pemotongan plat

\section{PENDAHULUAN}

Menurut ILO (International Labour Organization) pada tahun 2018 lebih dari 1,8 juta kematian akibat kerja terjadi setiap tahunnya di kawasan Asia dan Pasifik, bahkan dua pertiga kematian akibat kerja di dunia terjadi di Asia. Di tingkat global, lebih dari 2,78 juta orang meninggal setiap tahun akibat kecelakaan atau penyakit akibat kerja. Selain itu, terdapat sekitar 374 juta cedera dan penyakit akibat kerja yang tidak fatal setiap tahunnya, yang banyak mengakibatkan absensi kerja.(1)

Di Indonesia, berdasarkan data kementerian kesehatan jumlah kasus kecelakaan akibat kerja tahun 2011-2014 yang paling tinggi pada 2013 yaitu 35.917 kasus kecelakaan kerja (Tahun $2011=9.891$; Tahun $2012=21.735$; Tahun $2014=24.910$ ) (Kemkes, 2016).(2)
Provinsi dengan jumlah kasus kecelakaan akibat kerja tertinggi pada tahun 2011 adalah Provinsi Banten, Kalimantan

Tengah dan Jawa Timur. Tahun 2012 adalah Provinsi Jambi, Maluku dan Sulawesi Tengah. Tahun 2013 adalah Provinsi Aceh, Sulawesi Utara dan Jambi; tahun 2014 adalah Provinsi Sulawesi Selatan, Riau dan Bali. (OSHA, 2016). Data Badan Penyelenggara Jaminan Sosial (BPJS) Ketenagakerjaan Wilayah Sulawesi dan Maluku memperlihatkan, kecelakaan kerja tiga tahun terakhir mengalami peningkatan drastis. Pada 2015 terdapat 780 kasus, 2016 turun tipis 747 kasus, namun naik drastis pada 2017 menjadi 943 kasus. (BPJS, 2017).(3)

Penelitian yang dilakukan oleh Anshari dan Nizwardi (2016) jumlah pekerja konstruksi yang mengalami kecelakaan kerja lebih tinggi daripada 
yang tidak mengalami kecelakaan. Penelitian yang dilakukan Affidah dan Vivien (2016) para pekerja cenderung mengalami kecelakaan kerja, luka terbanyak yang dialami oleh karyawan adalah luka ringan (injury). Penelitian yang dilakukan oleh Messah, dkk (2015) jenis kecelakaan yang banyak dialami karena tergelincir dan terpleset.(4)

Faktor angka kecelakaan kerja yang terus menunjukkan tren meningkat ialah terdapatnya potensi bahaya di tempat kerja. Untuk meminimalisasi potensi bahaya keselamatan dan kesehatan kerja dapat dilakukan dengan melakukan identifikasi bahaya yang terdapat di lingkungan kerja. Faktor bahaya dalam lingkungan kerja yaitu golongan fisik, kimiawi, biologis atau psikososial (Salawati, 2015). (5)

Dalam era perdagangan bebas, identifikasi bahaya merupakan suatu keharusan untuk untuk dilaksanakan oleh penyelenggara kerja untuk meningkatkan produktivitas di lingkungan kerja. Jika kesehatan pekerja terpelihara dengan baik maka angka kecelakaan kerja dapat diminimalkan sehingga akan terwujud pekerja yang sehat dan produktif. Untuk mengurangi atau menghilangkan bahaya yang dapat menyebabkan kecelakaan di tempat kerja maka diperlukan suatu manajemen risiko yang kegiatannya meliputi identifikasi bahaya, analisis potensi bahaya maka penilaian risiko, pengendalian risiko, serta pemantauan dan evaluasi. (6)

Manajemen K3 adalah upaya terpadu untuk mengelola risiko yang ada dalam aktivitas perusahaan yang dapat mengakibatkan cidera pada manusia, kerusakan atau gangguan terhadap bisnis perusahaan. Manajemen risiko terbagi atas tiga bagian yaitu Hazard Identification, Risk Assessment and Risk Control (HIRARC). Metode ini merupakan bagian dari manajemen risiko dan yang menentukan arah penerapan K3 dalam perusahaan (Ramli, 2010). Hazard Identification, Risk Assessment and Risk Control (HIRARC) bertujuan untuk mengidentifikasi potensi bahaya di tempat kerja yaitu dengan mengaitkan antara pekerja, tugas, peralatan kerja dan lingkungan kerja. (OHSAS 18001: 2007).

Berdasarkan data survei awal (studi pendahuluan) di PT. Ikatan Kapal Indonesia (IKI) Makassar dengan mewawancarai manager K3LH, sebagian besar proses produksi kapal memiliki tingkat risiko kecelakaan kerja yang tinggi. Pada tahun 2012, data kecelakaan kerja yang terjadi di PT. Ikatan Kapal Indonesia (IKI) Makassar sebanyak 4 orang, tahun 2013 sebanyak 1 orang, tahun 2014 sebanyak 3 orang dan 2015 meningkat sebanyak 8 orang. Hal ini dikuatkan oleh pernyataan bagian proses produksi di PT. Ikatan Kapal Indonesia (IKI) Makassar bahwa kecelakaan kerja sebagian besar terjadi pada proses marking pada proses pemotongan pipa dan plat. Potensi bahaya yang dapat timbul adalah jari tangan terpotong, kejatuhan bahan produksi dan terjadinya LBP (Low Back Pain) akibat meja kerja yang tidak ergonomis. Selain itu kecelakaan kerja disebabkan karena kurangnya kesadaran pekerja tentang pentingnya menggunakan APD (Alat Pelindung Diri) pada saat bekerja, meskipun perusahaan telah menyediakan APD (Alat Pelindung Diri). (8)

Berdasarkan uraian sebelumnya maka peneliti tertarik untuk mengkaji tentang Analisis Risiko Kecelakaan Kerja Pada Pekerja Di PT. IKI Makassar Tahun 2020 (Studi Pada Pekerja Proses Marking).(9)

\section{METODE PENELITIAN}

Jenis penelitian yang digunakan yaitu kualitatif. Pendekatan yang digunakan dalam penelitian ini adalah pendekatan quasi kualitatif. Pendekatan quasi kualitatif adalah suatu metode penelitian yang melihat obyek/kondisi, gambaran, secara sistematis, faktual, dan akurat mengenai fakta yang diselidiki. Tehnik yang digunakan adalah observasi, wawancara mendalam (Indepth Interview) dan dokumentasi secara terus menerus selama penelitian berlangsung untuk menganalisis lebih 
dalam tentang identifikasi risiko dan pengendalian yang dapat dilakukan pada proses marking di PT. IKI Makassar.

Sebelum dilakukan penelitian secara kualitatif, proses manajemen risiko diukur menggunakan metode HIRARC (Hazard Identification, Risk Assessment and Risk Control) untuk mengidentifikasi bahaya pada setiap tahapan proses produksi yang mengacu pada standar AS/NZS 2001 yaitu Australia Standard/ New Zealand Standard.

\section{HASIL}

Penelitian ini dilaksanakan bulan Juni 2020 di PT. IKI Makassar. Subjek dalam penelitian ini Informan dalam penelitian ini sebanyak 8 orang yang terbagi dalam tiga bagian yaitu informan kunci yaitu inspektor $\mathrm{K} 3$, informan biasa (bagian dari manajemen proses produksi dan mengetahui alur proses produksi marking), dan informan pendukung (pekerja yang bekerja di bagian proses produksi marking) di PT. IKI Makassar.

Tabel 1. Karakeristik Informan di PT IKI Makassar Tahun 2020

\begin{tabular}{|c|c|c|c|c|c|}
\hline Inisial & Jabatan & Pendidikan & $\begin{array}{c}\text { Jenis } \\
\text { Kelamin }\end{array}$ & Umur & Informan \\
\hline$\overline{\mathrm{AN}}$ & $\begin{array}{l}\text { Inspektor K3 } \\
\text { Departemen }\end{array}$ & $\overline{S 1}$ & $\mathrm{~L}$ & 49 & Kunci \\
\hline SS & $\begin{array}{l}\text { Produksi (Manager } \\
\text { Lambung dan Pipa) } \\
\text { Departemen }\end{array}$ & S2 & $\mathrm{L}$ & 44 & Biasa \\
\hline $\mathrm{SCH}$ & $\begin{array}{l}\text { Produksi (Kepala } \\
\text { Proyek) }\end{array}$ & S1 & $\mathrm{L}$ & 47 & Biasa \\
\hline AI & $\begin{array}{c}\text { Departemen } \\
\text { Produksi (Kepala } \\
\text { Proyek Departemen } \\
\text { Pembangunan Baru) }\end{array}$ & S1 & $\mathrm{L}$ & 32 & Biasa \\
\hline SA & $\begin{array}{c}\text { Departemen } \\
\text { Produksi (Planner) }\end{array}$ & S1 & $\mathrm{L}$ & 30 & Biasa \\
\hline $\mathrm{R}$ & $\begin{array}{l}\text { Pekerja Bagian } \\
\text { Marking }\end{array}$ & SMA & $\mathrm{L}$ & 48 & Pendukung \\
\hline SL & $\begin{array}{l}\text { Pekerja Bagian } \\
\text { Marking }\end{array}$ & SMA & $\mathrm{L}$ & 49 & Pendukung \\
\hline AA & $\begin{array}{l}\text { Pekerja Bagian } \\
\text { Marking }\end{array}$ & SMA & $\mathrm{L}$ & 50 & Pendukung \\
\hline
\end{tabular}

\section{Identifikasi Risiko Kecelakaan Kerja}

Hasil wawancara yang dilakukan kepada informan pendukung selaku pekerja di bagian proses marking diperoleh informasi bahwa potensi bahaya yang sering terjadi pada pekerja yaitu terpeleset, terjatuh, dan tangan teriris.

"Paling sering itu kalo disini teriris tangan toh kalau memotong meki itu pipa, tapi tidak sampe ji ada yang parah. Alatnya itu dipake itu caranya meletakkan alat dijelaskan gurinda karena pipa baja dipotong paling lama itu 5 menit satu pipa, Kalo soal APD disini ada semua tapi itu mi kalau kerjaki lain-lain kita rasa terbiasa meki begitu dan lebih nyaman kalau tidak pake APD”. (SL, 49 tahun)

Pada wawancara berikutnya terkait dengan ketersediaan SOP, dimana SOP sudah tesedia di setiap proses produksi namun terkadang pekerjaan tidak sesuai SOP. Berikut kutipan wawancara dengan salah satu informan biasa selaku manager proses produksi :

"Pastilah sesuai, cuman kalau ada pelanggaran-pelanggaran kecil pasti adalah, pengambilan material itu harus ada lengkap tanda tangan, bisa saja kita langgar, yang penting sudah ada mengetahui satu orang tapi itukan masih dimaklumilah" (SS, 43 tahun).

Wawancara berikutnya terkait dengan pelanggaran SOP penandatanganan proyek dibenarkan oleh kepala proyek selaku informan biasa. Berikut kutipan wawancara dengan salah satu informan biasa selaku kepala proyek :

"Iya, untuk tanda tangan proyek untuk hal ini bisa dibenarkan. Pada kondisi tertentu. harus dipahami dulu regulasi tiap galangan beda beda. Itu akan dianggap pelanggaran jika di biasakan tapi untuk percepatan delivery yah saya benarkan termasuk mewakili saya untuk ttd" (AI, 32 tahun)

Selain itu, peneliti juga melakukan triangulasi sumber kepada informan kunci terkait dengan perilaku pekerja saat bekerja potensi bahaya yang timbul pada proses marking umumnya adalah kecelakaan kecil yang langsung di tangani sendiri oleh poliklinik perusahaan. Berikut kutipan wawancara dengan informan kunci selaku HSE (Inspekto K3) :

"Kecelakaan kerja yang sering itu terjatuh, tergelincir yah, tersandung, tertimpa. Untuk pencegahan risikonya 
pada pekerja sebelum memulai pekerjaan (briefing), kalau sudah terjadi pada pekerja itu dilakukan oleh P3K melihat risiko yg terjadi pada tubuh kalau tergores biasanya langsung di kasi alcohol baru diplaster kalau lebih para kita bawa ke rumah sakit." (AN, 49 tahun)
Berdasarkan hasil penelitian yang dilakukan di PT. IKI Makassar potensi bahaya paling tinggi pada Proses Marking dengan menggunakan metode HIRARC terdapat pada pemotongan pipa yang dapat dilihat pada tabel berikut :

Tabel 2. Identifikasi Potensi Bahaya Proses Marking di PT. IKI Makassar

\begin{tabular}{|c|c|c|}
\hline No & Kegiatan & Potensi Bahaya \\
\hline 1 & Pemotongan & Anggota tubuh terluka (teriris. Tergores, terpotong) \\
\hline & Pipa & $\begin{array}{l}\text { Tubuh tertimpa bahan material (produk) } \\
\text { Gangguan penglihatan akibat debu logam yang dihasilkan dari } \\
\text { pemotongan pipa }\end{array}$ \\
\hline 2 & $\begin{array}{l}\text { Pemotongan } \\
\text { Plat }\end{array}$ & $\begin{array}{l}\text { Low Back Pain (LBP) akibat meja kerja tidak ergonomis } \\
\text { Anggota tubuh terluka (jari terpotong) }\end{array}$ \\
\hline
\end{tabular}

Berdasarkan tabel 2 terdapat 2 potensi bahaya dan risiko kategori Medium Risk saat aktifitas pemotongan pipa, dan terdapat 3 potensi bahaya dan risiko kategori Low Risk saat aktifitas pemotongan plat di proses marking. Potensi bahaya dan risiko kecelakaan kerja yang termasuk dalam kategori Medium Risk merupakan risiko yang dapat ditoleransi, namun diperlukan control untuk dapat menurunkan sampai tahap yang lebih rendah. Sedangkan potensi bahaya dan risiko kecelakaan kerja yang termasuk dala kategori Low Risk merupakan risiko yang ditoleransi.

Berdasarkan penjabaran dan triangulasi teknik yang dilakukan peneliti terhadap hasil observasi dan wawancara ditemukan bahwa secara keseluruhan hasil wawancara dari informan kunci, informan pendukung dan informan biasa, beberapa informan memiliki pendapat yang berbeda, dimana sebagian mengatakan bahwa dalam melaksanakan pekerjaan, pekerja telah memakai APD, sedangkan sebagian besar informan mengatakan bahwa masih terdapat pekerja yang tidak menggunakan APD.

Adapun penyebab pekerja tidak patuh untuk menggunakan APD saat bekerja menurut peneliti, adanya sanksi yang belum efektif dan kurangnya ketegasan dari pihak K3 terkait hal tersebut. Selain itu, kurangnya pengawasan dan penyampaian informasi kepada pekerja tentang bahaya dan risiko kecelakaan kerja yang dapat terjadi di setiap proses produksi.



Gambar 1. Pekerja yang tidak menggunakan APD saat bekerja

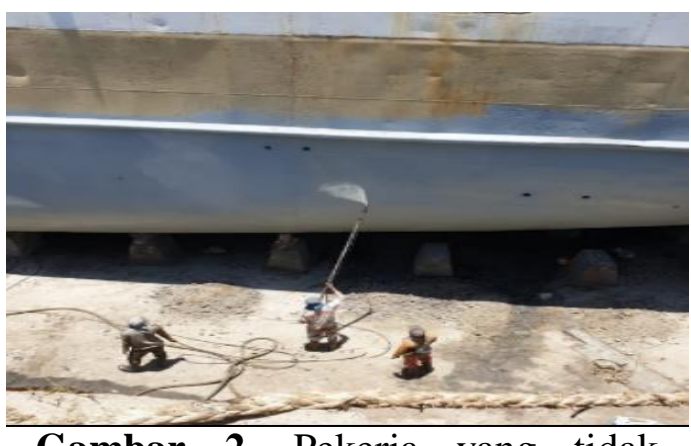

Gambar 2. Pekerja yang tidak menggunakan Helm saat pengecatan kapal 


\section{PEMBAHASAN}

Berdasarkan hasil observasi, terdapat beberapa pekerja yang melakukan tindakan tidak aman (unsafe act). Tindakan tidak aman tersebut yaitu bekerja tidak sesuai dengan SOP. Saat diwawancara kenapa bekerja tidak sesuai dengan SOP dikarenakan pekerja terburu-buru ingin cepat pulang. Kemudian ada beberapa pekerja yang tidak menggunakan APD (Alat Pelindung Diri) pada saat bekerja. Saat diwawancara kenapa bekerja tidak memakai APD dikarenakan pekerja telah merasa nyaman dan terbiasa tanpa menggunakan APD.

Berdasarkan hasil wawancara yang dilakukan, unsafe condition terjadi saat hujan karena saat hujan jalanan licin dan dapat menyebabkan pekerja terpeleset.

\section{Identifikasi Risiko Kecelakaan Kerja}

Hasil wawancara dan observasi yang dilakukan, diperoleh beberapa potensi bahaya secara umum yaitu bahaya mekanik, bahaya fisik, dan ergonomic. Bahaya mekanik yang ada pada area marking yaitu terjepit, terjatuh, tergores, teriris, terbentur tertimpa bahan produksi yang digunakan. Bahaya fisik diantaranya cedera, gangguan otot, keseleo, low back pain, dll. Bahaya fisik lain yaitu panas matahari dan hujan karena bekerja diluar ruangan. Bahaya ergonomi yaitu posisi duduk yang tidak sesuai dengan tempat duduk seadanya dan tidak disesuaikan dengan pekerja. Banyak risiko yang mungkin dapat terjadi dari akibat pemotongan plat dan pemotongan pipa, tetapi tidak disadari dan tidak dilaporkan oleh pekerja selama mereka masih nyaman dan bisa mengerjakan tugas mereka dengan baik. Sehingga ketika nyeri pinggang (LBP) pekerja hanya istirahat sebentar sambil meregangkan badan. Adapun pengendalian yang dapat dilakukan yaitu membuat tempat duduk yang lebih nyaman dan sesuai dengan posisi atau postur tubuh pekerja. Selain itu, untuk kecelakaan kerja yang biasa terjadi seperti teriris dan tergores dari pihak K3 menjelaskan bahwa hal itu dilakukan dan dikendalikan sendiri oleh perusahaan dengan membawa pekerja ke poliklinik untuk dilakukan pengobatan. Pencegahannya, pihak K3 mengatakan melakukan pembatasan penggunaan alat atau mesin dengan menyediakan sekat (penghalang) agar tidak langsung terpapar dengan pekerja dan untuk mengurangi getaran yang dihasilkan oleh alat yang dipakai untuk memotong, pihak K3 telah melakukan rekayasa engineering dengan memberikan dudukan pada alat sehingga getaran yang semula $35 \mathrm{~dB}$ bisa dikurangi menjadi 30-25 dB. Selain itu perusahaan juga telah menyediakan berbagai perlengkapan APD (Alat Pelindung Diri) untuk bekerja.

Penelitian ini sejalan dengan penelitian yang dilakukan Willy Tambunan (2018) tentang Analisis Risiko Keselamatan dan Kesehatan Kerja Menggunakan Metode Hirarc pada Proses Perbaikan Kapal Tugboat (Studi Kasus PT Marga Surya Shipindo, Samarinda), diperoleh beberapa potensi bahaya yaitu bahaya fisik, bahaya mekanik, bahaya kebiasaan, dan bahaya lingkungan. Bahaya mekanik berupa terjatuh, luka ringan, terpeleset, tergores, tertimpa bahan material. Bahaya fisik berupa, gangguan otot, low back pain akibat posisi kerja yang salah. Sedangkan bahaya lingkungan berupa gangguan pendengaran akibat suara gerinda. Walaupun kebisingan tidak berlangsung secara terus menerus tetapi hal tersebut merupakan potensi bahaya.

Hasil penelitian ini sesuai dengan teori domino yang dikembangkan oleh H.W Heinrich (1931) dalam (Salamidkk, 2016) yang menyatakan bahwa, kecelakaan kerja disebabkan oleh perilaku tidak aman (unsafe act) $88 \%$, kondisi tidak aman (unsafe condition) $10 \%$ dan "acts of God" $2 \%$ 
atau tidak dapat dihindari. Terdapat 5 faktor kecelakaan kerja sesuai dengan teori domino yaitu : lingkungan social, kesalahan pekerja, perilaku tidak aman (unsafe act) dan kondisi tidak aman (unsafe condition), kecelakaan dan cedera/jejas dan kerusakan. Sedangkan hasil observasi di PT. IKI Makassar kecelakaan kerja disebabkan karena faktor lingkungan sosial dimana kondisi lingkungan di PT. IKI Makassar sangat panas dan dekat dengan laut, kedua disebabkan faktor kesalahan pekerja, dimana pekerja terkadang tidak menggunakan APD, dan melintas pada rambu-rambu yang telah dilarang, dll

Hasil observasi yang didapatkan dari segi kesehatan lingkungan kerja, PT. IKI Makassar telah menyediakan pemilahan limbah padat non B3 baik itu organik, non organik \& B3 serta penampungan Limbah padat (Besi), telah terdapat penampungan limbah B3 yang membuat lingkungan kerja menjadi sehat serta mengurangi dampak pencemaran lingkungan hidup. Adapun dari segi kecelakaan kerja perusahaan telah memilki dokumen SOP dan risk assessment, pihak K3 telah melakukan pencatatan setiap kecelakaan yang terjadi diperusahaan dan telah melakukan pengendalian kecelakaan kerja yang terjadi. Namun masih terdapat beberapa kekurangan dimana APAR yang disediakan perusahaan tidak di tempatkan dengan semestinya dan tersembunyi. Selain itu, dilingkungan tempat kerja belum terdapat informasi statistic kecelakaan kerja, dan rambu-rambu K3 yang terdapat diperusahaan masih kurang dan tidak terawat.

\section{a. Pemotongan Pipa}

Berdasarkan hasil wawancara dan observasi yang dilakukan diperoleh beberapa potensi bahaya dan risiko yang dapat terjadi dengan tingkat bahaya yang sedang yaitu, teriris, tergores, posisi kerja yang salah, terpeleset yang dapat mengakibatkan jari dapat terpotong, cedera, luka, low back pain dan patah tulang.
Berdasarkan tabel HIRARC, potensi bahaya dan risiko yang terjadi pada pemotongan pipa belum dikategorikan sebagai high risk dikarenakan belum terdapat kecelakaan kerja yang parah, dan mengganggu system kerja di setiap proses pekerjaan. Hal ini disebabkan karena manajemen risiko yang dilakukan di PT. IKI Makassar sudah cukup baik dengan mengurangi dan mencegah terjadinya risiko kecelakaan kerja. Seperti pendapat dari inspector K3 yang mengatakan bahwa perusahaan telah melakukan pengendalian berupa rekayasa engineering, dengan memberikan sekat pada mesin sehingga tidak bersentuhan langsung dengan pekerja, pengendalian administratif berupa pemberian briefing untuk mengenalkan dan memberi tahu pekerja tentang risiko yang dapat terjadi disetiap pekerjaan yang akan dilakukan dan penyediaan APD yang diwajibkan bagi setiap pekerja.

\section{b. Pemotongan Plat}

Berdasarkan hasil wawancara dan observasi yang dilakukan diperoleh beberapa potensi bahaya dan risiko yang dapat terjadi dengan tingkat bahaya yang rendah yaitu teriris, tergores, yang dapat menyebabkan jari dapat terpotong. Berdasarkan tabel HIRARC, potensi bahaya dan risiko yang terjadi pada pemotongan pipa hanya dikategorikan low risk karena kecelakaan kerja tidak sering terjadi dan belum terdapat kecelakaan yang parah sehingga belum memerlukan penanganan lebih lanjut. Selain itu, pihak perusahaan sudah cukup baik menerapkan manajemen risiko $\mathrm{K} 3$ dengan mengatasi sendiri hal-hal kecil atau kecelakaan kerja yang tidak perlu dilakukan penanganan lebih lanjut berupa teriris tergores terjatuh, dll dengan menyediakan polikliklinik bagi pekerja, sehingga pekerja yang mengalami kecelakaan 
kerja langsung dibawa ke poliklinik untuk diobati dan semua disediakan secara gratis bagi pekerja perusahaan di PT. IKI Makassar.

\section{UCAPAN TERIMA KASIH}

Penulis ingin menyampaikan ucapan terima kasih kepada pembimbing, PT. IKI Makassar, informan penelitian yang telah bersedia untuk berpartisispasi tanpa adanya paksaan dari pihak manapun.

\section{KESIMPULAN}

Berdasarkan hasil penelitian Identifikasi Risiko Kecelakaan Kerja pada Pekerja di PT. IKI Makassar Tahun 2020 (Studi Pada Pekerja Proses Marking) dapat disimpulkan bahwa potensi bahaya yang terdapat pada proses marking di PT. IKI Makassar meliputi bahaya mekanik yang ada pada area marking yaitu terjepit, terjatuh, tergores, teriris, terbentur dan tertimpa bahan produksi yang digunakan. Bahaya fisik diantaranya cedera, gangguan otot, keseleo, low back pain, dll. Bahaya fisik lain yaitu panas matahari dan hujan karena bekerja diluar ruangan. Bahaya ergonomi yaitu posisi duduk yang tidak sesuai dengan tempat duduk seadanya dan tidak disesuaikan dengan pekerja.

\section{REFERENSI}

1. [AS/NZS 4801:2001] Australian Standard/New Zealand Standard 4801. 2001. Occupational Health and Safety Management -Specification with Guidance for Use. Sidney. ISBN 0 733740928.

2. BPJS Ketenagakerjaan. 2018. Info BPJS Ketenagakerjaan di Indonesia. BPJS Ketenagakerjaan.

3. Edwin, Tiffany. 2019. Analisis Resiko Pada Bagian Produksi Pabrik Pengolah Getah Karet Menggunakan Metode Hirarc (Studi Kasus Pt X Kota Padang. Jurnal Sains dan Teknologi 18 (1), Maret 2019: 21 - 26 P-ISSN 1412-6257 E-ISSN 2549-9472
4. Ihsan, Taufiq, Tivany Edwin, Reiner Octavianus Irawan. 2016. Analisis Risiko K3 Dengan Metode Hirarc Pada Area Produksi PT Cahaya Murni Andalas Permai. Jurusan Teknik Lingkungan Fakultas Teknik Universitas Andalas Kampus Unand Limau Manis, Padang, Sumatra Barat. P-Issn 1978-3833 E-ISSN 2442-6725 10(2)179-185 @2016 JKMA

5. International Labour Organization. 2013. Keselamatan dan Kesehatan Kerja Sarana untuk Produktivitas. Modul Lima, Jakarta

6. Karundeng, Intan. Analisis Bahaya Dan Risiko Dengan Metode HIRARCH Di Departement Production PT. Samudera Mulia Abadi Mining Contractor Likupang Minahahsa Utara. Jurnal KESMAS, Volume 7 Nomor 4

7. Kementerian Kesehatan RI "Situasi Kesehatan Kerja", Pusat Data dan Informasi Kementerian Kesehatan RI, 2015

8. Kurniawan, Andri, Mardi Santoso, Mey Rohma Dhani. Identifikasi Bahaya Pada Pekerjaan Maintenance Kapal Menggunakan Metode HIRARC dan FTA Dengan Pendekatan Fuzzy di Industri Kapal. Proceeding 1st Conference on Safety Engineering and Its Application ISSN No. 2581 - 1770

9. Peraturan Menteri Tenaga kerja No. Per 05/Men/2003. Sistem Manajemen Keselamatan dan Kesehatan Kerja. Jakarta: Depnaker RI, Dirjen Pembinaan hubungan Industrial dan pengawasan Ketenagakerjaan; 2003.

10. Restuputri, D. P. (2017). Identifikasi Dan Pengendalian Risiko Di Bagian Produksi 1 Dalam Upaya Pencapaian Zero Accident Menggunakan Metode Hazard Identification And Risk Assessment (Hira). Research Report

11. Samudra, Ragil Aji. Hazard Identification Risk Assessment and Risk Control dan Pemilihan Solusi Alternatif Menggunakan Benefit Cost Analysis (Studi Kasus: PT. Pelindo Marine Service). Proceeding 1st 
Conference on Safety Engineering and Its Application. ISSN No. 2581 1770

12. Salami, dkk, I.R.S., 2016. Kesehatan dan Keselamatan Lingkungan Kerja. Gadjah Mada University Press. Yogyakarta

13. Sitompul, Desi Rotua, Dwi Kartikasari. 2018. Analisis Penerapan Dan Usulan Perbaikan Sistem Manajemen Keselamatan Dan Kesehatan Kerja Di Pt Etowa Packaging Indonesia. Journal of Applied Business Administration Vol 2, No 2,September 2018, hlm. 166173.

14. Suma'mur.1989. Keselamatan Kerja dan Pencegahan Kecelakaan. Jakarta: CV. Haji Masagung

15. Suma'mur. 2014. Higiene Perusahaan dan Kesehatan Kerja (Hiperkes). Bandung: Sagung Seto

16. Tambunan, Willy, Fatria Ismi Zudha, Theresia Amelia Prawita. 2018. Analisis Risiko Keselamatan dan Kesehatan Kerja Menggunakan Metode Hirarc pada Proses Perbaikan Kapal Tugboat (Studi Kasus PT Marga Surya Shipindo, Samarinda). JIME (Journal of Industrial and Manufacture Engineering), 2 (2) November 2018 ISSN 2549-6328 (Print) ISSN 2549-6336 (Online)

17. Tarwaka. $2015 \quad$.Keselamatan Kesehatan Kerja dan Ergonomi (K3E) Dalam Perspektif Bisnis. Surakarta: Harapan Press

18. Tarwaka. $2016 \quad$.Dasar-dasar Keselamatan Kerja Serta Pencegahan Kecelakaan Di Tempat Kerja. Surakarta: Harapan Press

19. Transiska, Dewi.2015. Pengaruh Lingkungan Kerja Dan Faktor Manusia Terhadap Tingkat Kecelakaan Kerja Karyawan Pada pt. Putri Midai Bangkinang Kabupaten Kampar. Jom Fekon Vol 2 No. 1Februari 2015

20. Tualeka, Rohim Abdul. 2016. Hazards identification and risk assesment pada proses fabrikasi plate tanki 42-T501A. Surabaya.Jurnal Kesmas
Unair.Jurnal Fakultas Kesehatan Masyarakat. No 5. Vol 2. Universitas Airlangga. Hal $192-203$.

21. Undang-Undang Republik Indonesia Nomor 1 Tahun 1970 Tentang Keselamatan Kerja, (1970)

22. Widiastuti, R., Prasetyo, P. E., \& Erwinda, M. (2020). Identifikasi Bahaya Dan Penilaian Risiko Untuk Mengendalikan Risiko Bahaya Di Upt Laboratorium Terpadu Universitas Sarjanawiyata Tamansiswa. Industrial Engineering Journal of The University of Sarjanawiyata Tamansiswa, 3(2).

23. Wijaya, Albert. 2015. Evaluasi Kesehatan dan Keselamatan Kerja dengan Metode HIRARCpada PT. Charoen Pokphand Indonesia. Jurnal Titra, Vol3, No1,Januari 2015,pp.2934

24. Wulandari, Yulvina Rati. 2017. Penerapan Hirarc Sebagai Upaya Pencegahan Kecelakaan Kerja Pada Proses Produksi Garmen. Higeia Journal Of Public Health Research And Development. p ISSN 1475362846 e ISSN 1475-222656

25. Wursanto. 2005. Dasar-Dasar Ilmu Organisasi. Yogyakarta : Andi, Universitas Sumatra Utara 2012;(1 